Intervirology 1975-76;6:61

\title{
Note to Authors
}

Intervirology 6: 61 (1975/76)

New Review Process

At the Third International Congress for Virology held in Madrid in September 1975, it was decided to modify the review procedure for Intervirology.

For the first five volumes, each author selected the appropriate Section of the journal and submitted one copy of the paper to the Section Editor and a second copy to a reviewer of his choice. In this manner, the author was confident that his paper was being judged by persons whom he regarded as authorities in the area of the work being presented. The board member sent his review to the Section Editor, who also reviewed the paper and then made the decision to accept, modify, reject, or seek additional, anonymous review. The final judgment as to publication was made by the Section Editor in cooperation with the Editor-in-Chief. The new procedure will go into effect in volume 6 . To provide a consistent balance between known and anonymous reviewers, authors are now required as before to send one copy of their paper to an editorial board member. Essentially, the reviewer acts as the friend in court whom the author respects as an authority in the field. The author also sends the original and one copy to the Section Editor, who reads the original as before, but who now regularly sends out a copy for anonymous review. As before, referees send their reviews to the Section Editor, who together with the Editor-in-Chief continues to make the final judgment on publication.

The editors feel that the new procedure will continue to provide authors with their selected reviewer and at the same time will allow for nonpersonal anonymous evaluation in the decisionmaking process. 